\title{
Partner selection in public goods experiments
}

\author{
Giorgio Coricelli ${ }^{\mathrm{a}}$, Dietmar Fehr ${ }^{\mathrm{b}}$, Gerlinde Fellner ${ }^{\mathrm{c}}$
}

April 2003

\section{Detailed Abstract}

Mounting evidence on reciprocal behavior in various social interactions (e.g. Andreoni 1988, Fehr and Gächter 2000, Isaac and Walker 1988) suggests that the usually observed decline of cooperation in public goods experiments is mainly due to the influence of low contributors and reciprocal reaction of cooperators. Attempts to investigate this conjecture by regrouping individuals according to their predisposition in high and low contributing subgroups proved to enhance overall efficiency in the private provision of public goods (Gunnthorsdottir et al. 2001), mainly due to enduring high cooperation by the former subgroup. The reason why social dilemmas are quite well resolved in everyday life may be due to the fact that individuals can decide to quit their membership in an uncooperative group and choose their interaction partners themselves. Examples are various like moving to a new neighborhood, recruiting co-workers or choosing new members in sports teams.

Already Tiebout (1956) suggested that "voting with one's" feet, i.e. choosing the community that best satisfies one's preferences for collective goods, can solve the problem of market failures in efficiently providing public goods. Papers by Ehrhart and Keser (1999) and Page et al. (2002) have addressed this issue by providing the choice to switch one's group membership according to information about other groups or potential co-players with paying a small fixed cost. Both find efficiency increases and the desire of cooperators to be grouped with individuals of similar disposition.

Aside from some methodological drawbacks of these previous papers that we intended to avoid, our study focuses on the endogenous formation of pairs as the most fundamental form of groups. We introduce partner selection in a two-person public good experiment, where costs are endogenized by eliciting willingness to pay for selecting a partner. Subjects participate in six sequences of five rounds of a public good game in a partner design. At the end of each sequence a new partner can be selected out of a group of six. We employ

a CNRS-Université Claude Bernard Lyon, Institut des Sciences Cognitives, France, e-mail: gcoricelli@unisi.it

b University of Vienna, Department of Economics, Austria, e-mail: a9706955@unet.univie.ac.at

c Max Planck Institute for Research into Economic Systems, Strategic Interaction Group, Jena, Germany, e-mail: fellner@mpiewjena.mpg.de 
two different partner selection mechanisms, unilateral and mutual, and compare them to a baseline of random partner rematching.

Results demonstrate significantly higher contributions in correspondence to unilateral partner selection compared to mutual and random partner selections. Indeed, subjects contribute more and decrease their contributions less when they can unilaterally choose their partner. Whereas average willingness to pay for selecting a partner is significantly positive and remains even stable over time, cooperators and free-riders behave differently in the two mechanisms with respect to partner selection. The findings are important for understanding that not only considering endogenous partner selection is important in social dilemmas but also its way of implementation.

Keywords: public goods; partner selection; experiments

JEL-Classification: C91, D62, H41

\section{References}

Andreoni, J.: 1988, Why free-ride: Strategies and learning in public goods experiments, Journal of Public Economics 37, 291-304.

Ehrhart, K. and Keser, C.: 1999, Mobility and cooperation: On the run, CIRANO Working paper.

Fehr, E. and Gächter, S.: 2000, Fairness, and retaliation: The economics of reciprocity., Journal of Economic Perspectives 14, 159-81.

Gunnthorsdottir, A., Houser, D., McCabe, K. and Ameden, H.: 2001, Dispositional, history and contributions in public goods experiments, Working Paper. University of Arizona.

Isaac, M. R. and Walker, J.: 1988, Group size effects in public goods provision: The voluntary contributions mechanism, The Quarterly Journal of Economics 103, 179-199.

Page, T., Putterman, L. and Bulent, U.: 2002, Voluntary association in public goods experiments: Reciprocity, mimicry, and efficiency. Mimeo.

Tiebout, C. M.: 1956, A pure theory of local expenditures, Journal of Political Economy 64, 416-424. 